\title{
Indicators of intensive care unit capacity strain: a systematic review
}

\author{
Oleksa G. Rewa ${ }^{1,2^{*}}$, Henry T. Stelfox ${ }^{3,4,5,6}$, Armann Ingolfsson 7 , David A. Zygun 1,2,3, Robin Featherstone ${ }^{8}$, \\ Dawn Opgenorth ${ }^{1,3}$ and Sean M. Bagshaw ${ }^{1,2,3}$
}

\begin{abstract}
Background: Strained intensive care unit (ICU) capacity represents a fundamental supply-demand mismatch in ICU resources. Strain is likely to be influenced by a range of factors; however, there has been no systematic evaluation of the spectrum of measures that may indicate strain on ICU capacity.

Methods: We performed a systematic review to identify indicators of strained capacity. A comprehensive peer-reviewed search of MEDLINE, EMBASE, CINAHL, Cochrane Library, and Web of Science Core Collection was performed along with selected grey literature sources. We included studies published in English after 1990. We included studies that: (1) focused on ICU settings; (2) included description of a quality or performance measure; and (3) described strained capacity. Retrieved studies were screened, selected and extracted in duplicate. Quality was assessed using the NewcastleOttawa Quality Assessment Scale (NOS). Analysis was descriptive.

Results: Of 5297 studies identified in our search; 51 fulfilled eligibility. Most were cohort studies $(n=39 ; 76.5 \%)$, five (9.8\%) were case-control, three (5.8\%) were cross-sectional, two (3.9\%) were modeling studies, one (2\%) was a correlational study, and one (2\%) was a quality improvement project. Most observational studies were high quality. Sixteen measures designed to indicate strain were identified 110 times, and classified as structure $(n=4,25 \%)$, process $(n=7,44 \%)$ and outcome $(n=5,31 \%)$ indicators, respectively. The most commonly identified indicators of strain were ICU acuity ( $n=21 ; 19.1 \%$ [process]), ICU readmission ( $n=18 ; 16.4 \%$ [outcome]), after-hours discharge $(n=15 ; 13.6 \%$ [process]) and ICU census ( $n=13 ; 11.8 \%$ [structure]). There was substantial heterogeneity in the operational definitions used to define strain indicators across studies.
\end{abstract}

Conclusions: We identified and characterized 16 indicators of strained ICU capacity across the spectrum of healthcare quality domains. Future work should aim to evaluate their implementation into practice and assess their value for evaluating strategies to mitigate strain.

Systematic review registration: This systematic review was registered at PROSPERO (March 27, 2015; CRD42015017931).

Keywords: Quality, Safety, Adverse event, Indicator, Performance, Capacity, Strain, Organization, Intensive care unit

\section{Background}

Strained intensive care unit (ICU) capacity is conceptually defined as a discrepancy between the availability of ICU resources and demand to admit and provide highquality care for patients with critical illness $[1,2]$. ICU capacity strain is perceived to contribute to suboptimal

\footnotetext{
* Correspondence: rewa@ualberta.ca

'Department of Critical Care Medicine, Faculty of Medicine and Dentistry, University of Alberta, 2-124 Clinical Sciences Building, 8440 - 112th Street, Edmonton, AB T6G 2B7, Canada

${ }^{2}$ School of Public Health, University of Alberta, Edmonton, AB, Canada Full list of author information is available at the end of the article
}

care and may modify patient susceptibility to adverse events [3-5]. Strained capacity may influence clinician behavior and alter patient care processes [6,7]. Recent observations have suggested sustained strain may have negative consequences for ICU clinician wellbeing and the workplace environment [8].

Strained capacity is perceived among ICU professionals to be encountered more frequently due to growing demand for and relatively fixed supply of critical care services [1]. Moreover, strained capacity is perceived to contribute to inefficient healthcare resource use and to negatively 
impact the satisfaction that patients and families have with the healthcare they receive [1].

Strained ICU capacity is complex and likely influenced by a spectrum of patient-related, health care professionalrelated and health system-related factors. While selected indicators of capacity strain are well-described and are commonly used by healthcare systems (e.g., census, acuity, new admissions $[9,10])$; there has been no systematic interrogation of the literature to define the spectrum of indicators that may inform whether an ICU is experiencing strain.

Currently, there are few robust or validated indicators that quantify the immediate or temporal "stress" an ICU experiences due to strained capacity. Accordingly, we performed a systematic review and evidence synthesis to identify and characterize available indicators of strained ICU capacity. We believe this is an important initial step to develop evidence-informed indicators of strained capacity that may be implemented into routine practice to guide clinical care and policy.

\section{Methods}

We performed a systematic review using methodological approaches recommended in the Cochrane Handbook for Systematic Review of Interventions and described according to the PRISMA-P guidelines (Additional file 1) [11]. Health research ethics board approval was not required for this study. This systematic review was registered at PROSPERO (March 27, 2015; CRD42015017931) [12].

\section{Systematic review objectives}

The core aim of this review was to systematically evaluate the literature to identify proposed indicators of ICU capacity strain. The specific objectives included: (1) to generate an inventory of quality and performance indicators associated with strain on ICU capacity; and (2) to categorize these indicators of ICU capacity strain at the patient-level, ICU-level, and health system-level across attributes of quality indicators (i.e., importance; scientific acceptability; usability; feasibility) and the Donabedian framework (i.e., structure - where healthcare is delivered; process - how healthcare is delivered; outcome - the effects of the delivery of healthcare).

\section{Search strategy for identification of studies}

We developed a comprehensive search strategy in consultation with a research librarian (RF) that was peerreviewed by a second research librarian [13]. We searched the following electronic databases between August 11 and 24, 2015: Ovid MEDLINE (1946-), Ovid EMBASE (1988-), CINAHL Plus with Full Text via EBSCOhost (1937-), the Cochrane Library (inception-), including the Cochrane Database of Systematic Reviews, the Cochrane Central
Register of Controlled Trials (CENTRAL), and Web of Science Core Collection (1900-). We ran update searches in MEDLINE and EMBASE on February 1, 2017. Our search strategy combined the following concepts: (1) intensive care, critical care, critical illness, multi-organ dysfunction, multi-organ failure; (2) quality indicator, quality measure, performance indicator, quality improvement, quality assurance, quality control, performance improvement, best practice, processes of care, complications, adverse event, medication error, safety, effectiveness, efficiency, appropriateness, outcomes assessment, outcome, audit; and (3) strain, capacity, occupancy, census, resource, operations management, acuity, rationing, queuing, avoidable, unplanned, readmission, nighttime, discharge, absenteeism, burnout, workload, discrete event simulation (Additional file 2). Grey literature sources were searched for operations management reports, and selected conference proceedings (Additional file 3). Bibliographic records were exported to an EndNote X7 (Thomson Reuters, Philadelphia, PA, USA) database for screening.

Studies were included if they mentioned all of the following themes: (1) intensive care (i.e., intended to refer to patients (adults, children, and neonates) who are critically ill or at risk for an acute clinical deterioration that may necessitate support in an ICU setting); (2) quality or performance indicator (i.e., any measurable variable intended to evaluate the structure, process, or outcome of care provided to patients); (3) capacity strain (i.e., any measurable variable intended to evaluate the untoward impact at the patient-level, ICU-level, or heath-system level stress on ICU capacity due to the mismatch in demand and supply in our healthcare system). We considered studies published in English and after 1990. Finally, selected levels of evidence included all studies types (i.e., abstracts and full texts) reporting original primary and/or secondary data, as well as administrative reports to government or healthcare agencies.

We used a two-stage process for study selection [14]. First, two reviewers (OGR and SMB) independently screened the titles and abstracts (when available) of search results to determine whether a study fulfilled the general inclusion criteria. Disagreements were resolved by discussion. The full-text versions of all citations classified as "include" by either reviewer were retrieved for in-depth review. The same two reviewers (OGR and SMB independently assessed the eligibility of each fulltext manuscript for final inclusion into the review. Any disagreement was resolved by discussion.

\section{Data abstraction}

Two independent reviewers (OGR and SMB) extracted data using standardized, piloted, data extraction report 
forms. All strain indicators were identified, abstracted, and agreed upon by the two independent authors (OGR and SMB). The following data were abstracted from each citation: author identification, year of publication, title, journal of publication, study design, identified strain indicator(s), along with the operation definition and the relevance of each strain indicator.

Each strain indicator was characterized on its importance, scientific acceptability, usability and feasibility, as similarly performed previously by the authors [14]. Initially, $20 \%$ of retrieved citations $(n=20)$ had strain indicators described in duplicate to ensure consistency. Due to significant redundancy in strain indicators, the remainder of citations was extracted by a single reviewed (OGR) [14]. If there was uncertainty, strain indicators were reviewed in duplicate and consensus on its characteristics were achieved through discussion. Each strain indicator was stratified (yes/no) according to whether study authors described it as being importance (i.e., ICU quality, patient-centeredness, healthcare costs); described its scientific basis and rationale; and whether it was operationally usable and feasible (i.e., easy to indicator or implement; able to be integrated into an electronic health record [EHR]).

\section{Internal validity and risk of bias assessment}

We assessed the internal validity of included studies using the Newcastle-Ottawa Quality Assessment Scale (NOS), where studies are scored 0 to 9 based on quality [15]. Studies were rated high quality if they had a total score of 6-9, moderate quality with a score of 4-5, and poor quality if they had a score of 3 or fewer [14].

\section{Data analysis}

The primary analysis was descriptive. Strain indicators were categorized according to the Donabedian framework by stratifying whether each indicator represented a structure, process, or outcome related to ICU capacity strain [16]. Strain indicators were further evaluated by OGR and SMB using the four criteria proposed by the US Strategic Framework Board for a National Quality Measurement and Reporting System, as outlined above [17].

\section{Results}

Search results

Our initial search strategy identified 5297 citations, of which 51 articles satisfied eligibility criteria and were included (Fig. 1). Of these, 40 were full-text articles and 11 were presented in abstract form only (Additional File 4).

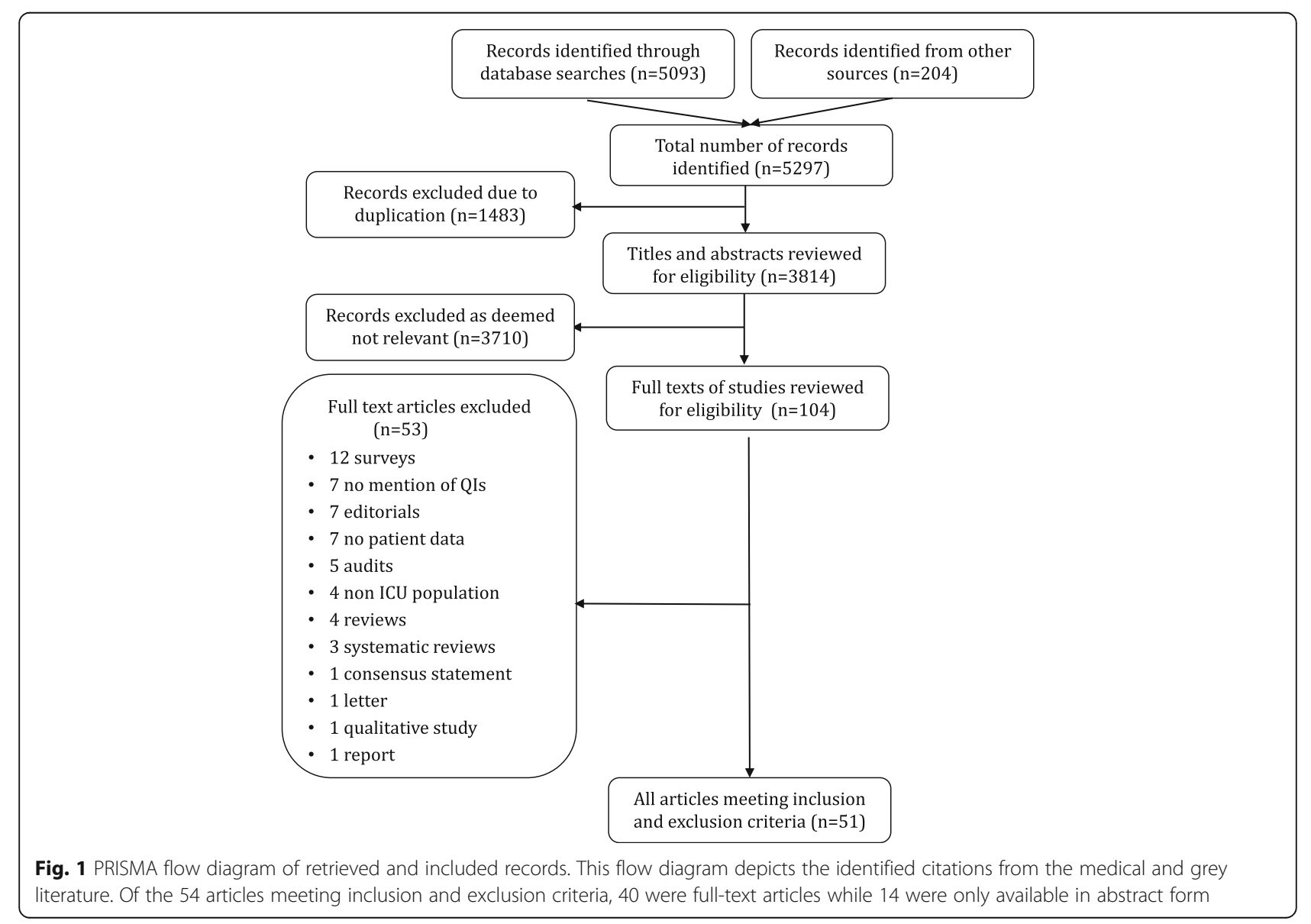


The majority were cohort studies $(n=39 ; 76.5 \%)$, five (9.8\%) were case-control, three $(5.8 \%)$ were cross-sectional, two $(3.9 \%)$ were modeling studies, one $(2 \%)$ was a correlational study, and one (2\%) was a quality improvement project (Table 1). Most studies were research in nature $(n=43$, $84.3 \%)$, while the remainder where quality improvement projects $(n=8,15.7 \%)$.

\section{Study quality}

The mean Newcastle-Ottawa quality score was 8.5 (range 4-9). The majority of full text studies were high quality $(n=36,90 \%)$, while a few were moderate quality ( $n=4,10 \%)$; with no observational studies rated as poor quality. Of the remaining studies identified $(n=11$, $21.6 \%$ ), quality assessment was not possible due to insufficient data as studies were only available in abstract form.

\section{Indicators of capacity strain}

A total of 16 potential strain indicators were identified 110 times in our included citations, and classified as structure $(n=4,25 \%)$, process $(n=7,44 \%)$ and outcome $(n=5,31 \%)$ indicators, respectively (Table 2$)$. The most commonly identified strain indicators were ICU acuity $(n=21 ; 19.1 \%$ [process] $)$, ICU readmission $(n=18$; $16.4 \%$ [outcome]), after-hours discharge $(n=15 ; 13.6 \%$ [process]) and ICU census ( $n=13 ; 11.8 \%$ [structure]). There was substantial heterogeneity in the operational definitions used to define strain indicators across studies (Table 2). Strain indicators were also stratified across the six dimension of healthcare quality: safety $(n=4 ; 25 \%)$; effectiveness $(n=3 ; 19 \%)$; patient-centeredness $(n=1$; $6 \%)$; timeliness $(n=3 ; 19 \%)$; efficiency $(n=4 ; 25 \%)$; and equitability $(n=1 ; 6 \%)[18]$.

\section{National quality measurement and reporting criteria}

Features of these potential strain indicators, as discussed by study authors, generally focused on importance as key ICU performance or quality indicators $(n=95 ; 74 \%)$, followed by scientific acceptability $(n=23 ; 24 \%)$ and then by usability and feasibility $(n=11 ; 12 \%)$ (Table 3$)$. Importance was further stratified across specific elements of capacity strain, including importance to patient-related outcomes $(n=47 ; 55 \%)$, importance as an indicator of ICU operations and organizational planning $(n=42 ; 44 \%)$, and importance to healthcare costs $(n=6 ; 6 \%)$. None of the studies presented data regarding the reliability or validity of the performance of the indicators.

\section{Discussion}

Strain on ICU capacity is complex; however, strain has recognized implications for the practice of critical care, consistently showing association with altered care processes, suboptimal care delivery, adverse patient outcomes, and a negative workplace environment [1]. In response to not being able to identify a prior appraisal characterizing indicators of strained ICU capacity, we performed a rigorous systematic review and evidence synthesis.

\section{Summary of key findings}

First, we identified 16 potential indicators of strained ICU capacity that encompassed all three domains of the Donabedian framework and quality dimensions. Second, we found that the operational definitions for strain indicators across studies were substantially heterogeneous. For example, we found 110 examples of indicators in our retrieved studies; and due to varied definitions, these were subsequently consolidated into related themes. Third, few studies had evaluated the scientific acceptability, usability or feasibility of the proposed strain indicators. Similarly, none of the studies identified specifically described the reliability or validity of the performance of these potential indicators of strain. Fourth, the most common strain indicators identified included indicators of ICU acuity, ICU readmission, after-hours discharge, and ICU census/occupancy. Notably, these strain indicators have considerable overlap with commonly recommended key indicators of ICU performance (KPI) [19, 20]. Finally, we also identified several indicators that while perhaps also analogous with some ICU KPIs, may also be suitable to characterize strained capacity conditions. These specific structure (e.g., queuing; nurse-to-patient ratios), process (e.g., bed turnover; workload; refusal rate) and outcome (e.g., healthcare professional burnout; surgery postponements) indicators could be evaluated over both the shortterm and intermediate-term to provide holistic data on contributors to and effects of strained ICU capacity.

\section{Context with prior literature}

Population growth, advances in medical science and improved capability to support critically ill patients have all translated into a sustained and rising demand for critical care services [21]. This increased demand; however, cannot be universally accompanied by an increased supply of ICU resources, which are costly [22]. The costs of expanding ICU extend beyond the "ICU bed" per se and necessitate considerable investment in human resources, specialized equipment (i.e., mechanical ventilators), and supplies to sustainably operate. Moreover, the supply side of ICU services is not standardized and are highly inconsistent across jurisdictions for reasons that are not based on evidence-informed scientific assessment of need [23, 24]. Regardless of the reasons, mismatches between demand and supply for ICU services are increasingly encountered [7]. This mismatch on any given day in any given ICU will create strain on that ICU's capacity to accommodate the next critically ill 
Table 1 Baseline characteristics of included trials

\begin{tabular}{|c|c|c|c|c|c|c|}
\hline Author & Source & Intent & Design & Population & (n) & Strain Measure \\
\hline Ahmed [1] & Abstract & Quality & Case-control & Adult & 161 & $\begin{array}{l}\text { After-hours discharge } \\
\text { queuing }\end{array}$ \\
\hline Ahrens [2] & Abstract & Research & Cohort & Pediatric & 764 & ICU census \\
\hline Al-Jaghbeer [3] & Full text & Quality & Cohort & Adult & 136 & $\begin{array}{l}\text { After-hours discharge } \\
\text { ICU readmission }\end{array}$ \\
\hline Amaravadi [4] & Full text & Research & Cohort & Adult & 366 & Nurse-to-patient ratio \\
\hline Aytekin [5] & Full text & Research & Correlational & Neonatal & 80 & Burnout \\
\hline Azevedo [6] & Abstract & Research & Cohort & Adult & 1329 & $\begin{array}{l}\text { ICU acuity } \\
\text { ICU readmission }\end{array}$ \\
\hline Beck [7] & Full text & Research & Cohort & Adult & 1654 & $\begin{array}{l}\text { After-hours discharge } \\
\text { ICU acuity }\end{array}$ \\
\hline Brown [8] & Full text & Research & Cohort & Adult & 268,824 & ICU readmission \\
\hline Brown [9] & Full text & Research & Cohort & Adult & 214,692 & ICU readmission \\
\hline Chalfin [10] & Full text & Research & Cross-sectional & Adult & 50,322 & Queuing \\
\hline Cooper [11] & Full tText & Research & Cohort & Adult & 103,984 & $\begin{array}{l}\text { ICU acuity } \\
\text { ICU readmission }\end{array}$ \\
\hline Czaja [12] & Full text & Research & Cohort & Pediatric & 111,923 & $\begin{array}{l}\text { After-hours discharge } \\
\text { ICU readmission }\end{array}$ \\
\hline Dara [13] & Full text & Research & Cohort & Adult & 2492 & $\begin{array}{l}\text { ICU acuity } \\
\text { Standardized mortality rate }\end{array}$ \\
\hline Duke [14] & Full text & Research & Cohort & Adult & 697 & After-hours discharge \\
\hline Duke [15] & Full text & Research & Cross-sectional & Adult & 24,935 & $\begin{array}{l}\text { ICU readmission } \\
\text { ICU transfer } \\
\text { Queuing } \\
\text { Surgery cancellation }\end{array}$ \\
\hline Duke [16] & Full text & Research & Cohort & Adult & 3004 & $\begin{array}{l}\text { ICU census } \\
\text { ICU refusal } \\
\text { Surgery cancellation }\end{array}$ \\
\hline Frankel [17] & Full text & Quality & Cohort & Adult & 4956 & ICU readmission \\
\hline Frisho-Lima [18] & Full text & Research & Cohort & Adult & 127 & ICU census \\
\hline Gajic [19] & Full text & Research & Cohort & Adult & 1131 & $\begin{array}{l}\text { ICU acuity } \\
\text { ICU readmission }\end{array}$ \\
\hline Gantner [20] & Full text & Research & Cohort & Adult & 109,384 & $\begin{array}{l}\text { After-hours discharge } \\
\text { ICU readmission }\end{array}$ \\
\hline Goldfrad [21] & Full text & Research & Case-control & Adult & 2269 & After-hours discharge \\
\hline Gopal [22] & Abstract & Research & Case-control & Adult & 1257 & $\begin{array}{l}\text { After-hours discharge } \\
\text { ICU readmission }\end{array}$ \\
\hline Harris [23] & Abstract & Research & Cohort & Adult & 13,086 & Queuing \\
\hline Heneghan [6] & Abstract & Research & Cohort & Pediatric & 373 & ICU readmission \\
\hline Hung [24] & Full text & Research & Cohort & Adult & 1242 & $\begin{array}{l}\text { ICU acuity } \\
\text { Queuing }\end{array}$ \\
\hline Iwashyna [25] & Full text & Research & Case-control & Adult & 200,499 & $\begin{array}{l}\text { ICU acuity } \\
\text { ICU census }\end{array}$ \\
\hline Joynt [26] & Full text & Research & Cohort & Adult & 624 & $\begin{array}{l}\text { ICU census } \\
\text { Standardized mortality rate }\end{array}$ \\
\hline Kramer [27] & Full text & Research & Cohort & Adult & 369,129 & $\begin{array}{l}\text { ICU acuity } \\
\text { ICU readmission }\end{array}$ \\
\hline Laupland [28] & Full text & Research & Cohort & Adult & 7380 & $\begin{array}{l}\text { After-hours discharge } \\
\text { ICU acuity }\end{array}$ \\
\hline Leary [29] & Full text & Quality & Modeling & Adult & 3101 & $\begin{array}{l}\text { ICU census } \\
\text { Standardized mortality rate } \\
\text { Workload }\end{array}$ \\
\hline
\end{tabular}


Table 1 Baseline characteristics of included trials (Continued)

\begin{tabular}{|c|c|c|c|c|c|c|}
\hline Author & Source & Intent & Design & Population & (n) & Strain Measure \\
\hline Lim [30] & Full text & Research & Cohort & Adult & 70 & ICU acuity \\
\hline Liu [31] & Full text & Research & Case-control & Adult & 6369 & ICU acuity \\
\hline Louriz [32] & Full text & Research & Cohort & Adult & 398 & $\begin{array}{l}\text { ICU acuity } \\
\text { ICU census }\end{array}$ \\
\hline Nathanson [33] & Full text & Research & Cohort & Adult & 124,855 & ICU acuity \\
\hline Parker [34] & Abstract & Research & Cohort & Adult & 255 & Queuing \\
\hline Pozzesseres [6] & Abstract & Research & Cohort & Adult & 210 & Queuing \\
\hline Priestap [35] & Full text & Research & Cohort & Adult & 47,062 & $\begin{array}{l}\text { After-hours discharge } \\
\text { ICU acuity }\end{array}$ \\
\hline Pronovost [36] & Full text & Research & Cohort & Adult & 2982 & $\begin{array}{l}\text { Daily rounds by intensivist } \\
\text { Nurse-to-patient ratio }\end{array}$ \\
\hline Rosenberg [37] & Full text & Research & Cohort & Adult & 4208 & $\begin{array}{l}\text { ICU acuity } \\
\text { ICU readmission } \\
\text { Standardized mortality rate }\end{array}$ \\
\hline Ruse [38] & Abstract & Quality & Cohort & Adult & Unknown & $\begin{array}{l}\text { After-hours discharge } \\
\text { ICU acuity } \\
\text { Queuing }\end{array}$ \\
\hline Santamaria [39] & Full text & Research & Cohort & Adult & 10,221 & $\begin{array}{l}\text { After-hours discharge } \\
\text { ICU acuity }\end{array}$ \\
\hline Singh [40] & Full text & Research & Cohort & Adult & 2300 & $\begin{array}{l}\text { After-hours discharge } \\
\text { ICU acuity } \\
\text { ICU readmission }\end{array}$ \\
\hline Stelfox [6] & Abstract & Research & Cohort & Adult & 32,234 & ICU readmission \\
\hline Tobin [41] & Abstract & Research & Cohort & Adult & 10,903 & $\begin{array}{l}\text { After-hours discharge } \\
\text { Early ICU discharge } \\
\text { ICU acuity } \\
\text { Queuing }\end{array}$ \\
\hline Town [42] & Full text & Research & Cohort & Adult & 60,355 & $\begin{array}{l}\text { ICU census } \\
\text { ICU readmission } \\
\text { Turnover } \\
\text { Workload }\end{array}$ \\
\hline Tucker [43] & Full text & Research & Cohort & Neonatal & 13,334 & $\begin{array}{l}\text { ICU census } \\
\text { Nurse-to-patient ratio } \\
\text { Turnover }\end{array}$ \\
\hline Wagner [44] & Full text & Quality & Cohort & Adult & 200,730 & $\begin{array}{l}\text { ICU acuity } \\
\text { ICU census } \\
\text { ICU readmission } \\
\text { Turnover }\end{array}$ \\
\hline West [45] & Full text & Research & Cross-sectional & Adult & 38,165 & $\begin{array}{l}\text { ICU census } \\
\text { Nurse-to-patient ratio } \\
\text { Turnover } \\
\text { Workload }\end{array}$ \\
\hline Yergens [38] & Abstract & Research & Cohort & Adult & 1770 & ICU census \\
\hline Amarasigham [46] & Full text & Quality & Quality Improvement & Adult & Unknown & Queuing \\
\hline Barado [47] & Abstract & Quality & Modeling & Adult & 6300 & $\begin{array}{l}\text { Early ICU discharge } \\
\text { ICU refusal }\end{array}$ \\
\hline
\end{tabular}

The characteristics of the included studies are included above. A full reference of included studies is included in Additional file 4.

ICU, intensive care unit

patient. Strained ICUs are at risk of providing suboptimal quality of care, and risk higher rates of adverse events, premature discharges, unplanned readmissions and death [4, 25-28]. Arguably, sustained strain contributes to inefficient and inequitable utilization of finite ICU resources. While opening additional ICU beds may seem the simplest response, this is not necessarily sustainable, and likely only a short-term reprieve [29]. Rather, in order to explain the breadth of effect strain may have on patients, professionals and operations, a constellation of evidence-informed quality indicators are likely to be necessary. 
Table 2 Summary of description and definitions for strain indicators across studies

\begin{tabular}{ll}
\hline Quality indicator & description \\
\hline ICU census & ICU bed occupancy \\
ICU bed availability
\end{tabular}

After-hours ICU discharge of a patient to the hospital ward outside discharges of regular hours.

Turnover

Workload

Early ICU discharge Premature ICU discharge.

Refusal rate A measure of the number of patients referred to but not admitted to the ICU.

ICU readmission Patients who have been discharged from the ICU and are readmitted within the same hospitalization.

SMR

Burnout

Job satisfaction

Surgery cancellation Elective surgeries that is postponed or cancelled due to ICU bed availability.
Definitions used in the literature for exposure,

outcome and analysis

- Total number of patients who spent at least $2 \mathrm{~h}$ in the

ICU on the calendar day the patient was admitted.

- Bed occupancy.

- ICU full and not able to admit or discharge any patients.

- No available ICU beds

- Delay in ICU admission.

- Delay in ICU admission > $4 \mathrm{~h}$.

- Delay in ICU admission $>6 \mathrm{~h}$.

- Delay in ICU admission $>8 \mathrm{~h}$.

- Mean time from bed request to ICU transfer.

- Ratio of nurses to beds in an ICU.

- Ratio > or < 1:2.

- Ratio 1:2 vs. 1:2.

- No definition provided.

- Inter-hospital transfer of an ICU patient.

- APACHE II score.

- Acute physiology score.

- MPM-0 score.

- ICU discharge between 1600 and $0800 \mathrm{~h}$.

- ICU discharge between 1800 and $0600 \mathrm{~h}$.

- ICU discharge between 2000 and $0800 \mathrm{~h}$.

- ICU discharge between 2200 and $0700 \mathrm{~h}$.

- Number of new admissions, discharges and transfers.

- Number of new admissions per day.

- Number of admissions in a given week.

- Number of new patient admissions and number of patient-care days.

- Volume and pressure of work.

- TISS score

- Discharged early but would have benefited from longer ICU stay.

- Patients who were referred to but not admitted to the ICU.

- ICU readmission within $24 \mathrm{~h}$.

- ICU readmission within $48 \mathrm{~h}$.

- ICU readmission within $72 \mathrm{~h}$.

- Unplanned ICU readmission.

- Not applicable.

- State characterized by physical and/or psychological fatigue, disappointment, underachievement, tiredness and desire to leave work.

- Nursing self-reports of either being satisfied, unsatisfied or partially satisfied.

- Cancellation of surgery due to lack of ICU bed.

- Surgery cancelled or rescheduled.

This table shows examples of varying definitions across the retrieved studies of the most common 'same' strain indicators

Abbreviations: APACHE Acute Physiology and Chronic Health Evaluation, ICU intensive care unit, MPM mortality prediction model, MRP most responsible physician, SMR standardized mortality ratio, TISS Therapeutic Intervention Scoring System,

Above are shown description of the context and specific definitions of the most common 'same' strain indicators from included studies. Selected strain measures (i.e., daily rounds by an intensivist; SMR) were not precisely defined and assumed 
Table 3 Categorization and relevance of identified quality indicators

\begin{tabular}{|c|c|c|c|c|c|c|}
\hline \multirow[t]{2}{*}{$\begin{array}{l}\text { Categorization of strain measure by } \\
\text { the Donabedian framework }\end{array}$} & \multicolumn{3}{|c|}{$\begin{array}{l}\text { Importance } \\
(n=95)\end{array}$} & \multirow{2}{*}{$\begin{array}{l}\text { Scientific } \\
\text { acceptability } \\
(n=23)\end{array}$} & \multicolumn{2}{|c|}{$\begin{array}{l}\text { Usability and feasibility } \\
(n=11)\end{array}$} \\
\hline & $\begin{array}{l}\text { Quality } \\
(n=42)\end{array}$ & $\begin{array}{l}\text { Patient-centered outcomes } \\
(n=47)\end{array}$ & $\begin{array}{l}\text { Healthcare costs } \\
(n=6)\end{array}$ & & Operational $(n=8)$ & $\begin{array}{l}\text { Integrate into EHR } \\
(n=3)\end{array}$ \\
\hline \multicolumn{7}{|l|}{ Structure $(n=30)$} \\
\hline 1. ICU census $(n=13)$ & 7 & 7 & 1 & 4 & 3 & 1 \\
\hline 2. Queuing $(n=11)$ & 2 & 3 & 1 & 3 & 1 & - \\
\hline 3. Nurse to patient ratio $(n=5)$ & 2 & 3 & 1 & 2 & 1 & - \\
\hline 4. Daily rounds by intensivist $(n=1)$ & 1 & 1 & - & - & - & - \\
\hline \multicolumn{7}{|l|}{ Process $(n=50)$} \\
\hline 5. ICU transfer $(n=1)$ & - & - & - & - & - & - \\
\hline 6. ICU acuity $(n=21)$ & 10 & 10 & - & 2 & - & - \\
\hline 7. After-hours discharge $(n=15)$ & 11 & 11 & 2 & 8 & 1 & - \\
\hline 8. Turnover $(n=4)$ & 2 & 2 & - & - & - & - \\
\hline 9. Workload $(n=4)$ & 1 & 1 & - & - & 1 & 1 \\
\hline 10. Early ICU discharge $(n=3)$ & - & - & - & - & - & - \\
\hline 11. Refusal rate $(n=2)$ & - & - & - & - & - & - \\
\hline \multicolumn{7}{|l|}{ Outcome $(n=30)$} \\
\hline 12. ICU readmission $(n=18)$ & 7 & 7 & 1 & 2 & - & - \\
\hline 13. $\operatorname{SMR}(n=4)$ & 1 & 1 & - & - & 1 & 1 \\
\hline 14. Burnout $(n=2)$ & - & - & - & 1 & - & - \\
\hline 15. Job satisfaction $(n=2)$ & - & - & - & 1 & - & - \\
\hline 16. Surgery cancellation $(n=2)$ & - & - & - & - & - & - \\
\hline
\end{tabular}

In the first column, the types of identified Qls are listed with the number of instances in parenthesis. In the subsequent columns the breakdown of the characteristics of the identified QIs as per the four criteria proposed by the United States Strategic Framework Board for a National Quality Measurement and Reporting System. Importantly, not all QIs had these characteristics described in the identified studies Abbreviations: EHR electronic health record, ICU intensive care unit, SMR standardized mortality ratio

${ }^{\dagger}$ Strain measures are stratified by structure, process, or outcome

"The number of instances that each quality indicator was deemed relevant as per the authors according to the US National quality measurement and reporting criteria are also listed

Many of the strain indicators identified in our review are highly correlated with commonly cited ICU KPI or quality indicators $[19,20]$. However, we contend many of these indicators have not been specifically evaluated in the context of strained operating conditions and capacity. Moreover, many will exhibit context-specific variation and require local or regional evaluation. Commonly described indicators of strain capacity, particularly occupancy/bed availability, acuity, and numbers of new admissions have repeatedly shown association with adverse outcomes, deviations in care processes, and changes in resource use $[3,5-7,9,10,30]$. However, it remains uncertain whether these alone may completely capture the spectrum of effects for how strain may manifest and exert its effects across heterogeneous ICU settings. Rather, they may put focus on queuing rather than on demand and the capacity to manage high flow and increased patient turnover, such as in specialized ICUs (i.e., cardiac surgery) [31]. Complementary indicators of strain may be important in such circumstances.
ICU readmission has been recognized as a potential indicator of strained ICU capacity [10]. While ICU readmission has been endorsed as a standard KPI for ICUs [19, 20]; there is uncertainty to its validity [32]. In a retrospective cohort study, Wagner et al. found greater strain, defined by average census, number of new ICU admissions, and ICU acuity, was associated with a shorter ICU stay and a small but significant increased risk for ICU readmission following discharge [10]. However, among those readmitted, there is uncertainty whether these events were avoidable or attributable to premature triage in response to strained conditions. Recent observations suggest the majority of ICU readmissions are not preventable or attributable to causal actions or omissions of the ICU team [33]. Further evaluation of ICU readmission as a potential indicator of strain should aim to integrate additional indicators of strain and adjudication of whether ICU readmission was avoidable. 


\section{Limitations}

While our rigorous review identified 51 studies that characterized a spectrum of indicators of strained capacity across a range of quality dimensions, some of which are likely routinely measured or should be implemented by ICUs, our findings should be considered in the context of the following limitations. The identified indicators across studies were variably defined, were often not the intended primary exposure, and the operational characteristics were incomplete described (e.g., elements identified in the US Strategic Framework Board for a National Quality Measurement and Reporting System) (Table 3). Further refinement and streamlining of definitions will be needed prior to operationalizing these potential identified strain indicators. Furthermore, as for the abovementioned reasons, pooled analyses across "strain indicators" were not feasible.

\section{Implications for healthcare professionals, health policy and research}

The challenge for healthcare professionals is to clearly understand when and to what extent strain is negatively impacting their decision-making, the quality of care provided and the performance of a given ICU, and to readily identify and respond to factors most responsible. Healthcare professionals should be particularly mindful of the influence strained ICU capacity may have to modify behaviours and care processes [5-7]. There is uncertainty on how best to measure strained capacity. While simple objective indicators such as ICU census/ occupancy are strongly perceived to indicate strain [34], the spectrum of how strain can manifest is likely far most complex and it is unlikely that any single indicator will satisfy all the potential domains from which strain may originate. Moreover, as a consequence, there may be limited appreciation for the collateral effect of strained capacity, such as a negative impact on ambulance offloads, emergency department crowding, and postponements of elective surgery.

Simple, translatable and easily reportable indicators are needed to identify and quantify strained capacity. Widespread implementation of electronic health records (EHR) and data repositories/registries have enabled the routine calculation and reporting of standard ICU KPIs [3]. Such infrastructure could be re-orientated to generate a concise dashboard or index consisting of strain indicators across multiple quality domains (Table 4). For example, 13 of our proposed indicators could readily be integrated into a strain dashboard. Additional potential indicators, including healthcare professional burnout (i.e., attribution, absenteeism, overtime), workplace satisfaction, patient-family satisfaction would require additional resources to integrate. We contend this is a fundamental step towards developing innovative quality
Table 4 Proposed dashboard of indicators for ICU strain

\begin{tabular}{ll}
\hline $\begin{array}{l}\text { Short-term measures } \\
\text { (e.g., daily or weekly) }\end{array}$ & $\begin{array}{l}\text { Intermediate term measures } \\
\text { (e.g., monthly or quarterly) }\end{array}$ \\
\hline ICU acuity & ICU readmission \\
After-hours discharges & Burnout \\
ICU census & Workplace satisfaction \\
Sedation interruption* & Early ICU discharge \\
Queuing & Surgery cancellation \\
Mobilization* & ICU transfer \\
Nurse-to-patient ratio & Refusal rate \\
Turnover & Adverse events* \\
Mechanical ventilation weaning* & SMR \\
Workload & Family satisfaction* \\
Daily rounds by intensivist &
\end{tabular}

Above are listed both short-term (i.e., measured daily) and intermediate-term (i.e., measured monthly or quarterly) QIs for ICU strain

Abbreviations: ICU intensive care unitSMR standardized mortality rate

*Proposed Qls that were not identified in our search strategy

improvement interventions aimed to improve safety (i.e., care processes, adverse events, nosocomial infections), effectiveness (i.e., SMR), timeliness (e.g., access, queuing), efficiency (e.g., flow, avoidable ICU days), and to better equip ICUs to anticipate and manage strained capacity. Future work should aim to evaluate the feasibility of implementing a constellation of strain indicators, evaluate the association of strain indicators on patient-centered and health resource outcomes, including impact on additional KPIs, establish threshold for optional strain indicator definitions and benchmarks (Table 5), recognizing some may be geographically and context-specific. Finally, future work should consider the development of indicators that try to capture the match between the demand and capacity, with the goals of having ICUs operate in an ideal range to limit both strain and healthcare inefficiencies.

\section{Conclusions}

Strained ICU capacity is likely to increasingly be encountered concomitant with growing demand for critical care and ICU resources. Strain negatively impacts a wide variety of care processes and outcomes for patients, families, healthcare professionals and the healthcare system. Identification of strained capacity is complex and ideally requires an evidence-informed set of indicators. We have characterized 16 indicators of strained ICU capacity across the spectrum of healthcare quality domains. Future work should focus on further rigorously defining indicated of strained capacity, on evaluating the acceptability and feasibility of implementation, and on assessing their value for identifying strain and evaluating interventions to manage strained ICU capacity. 


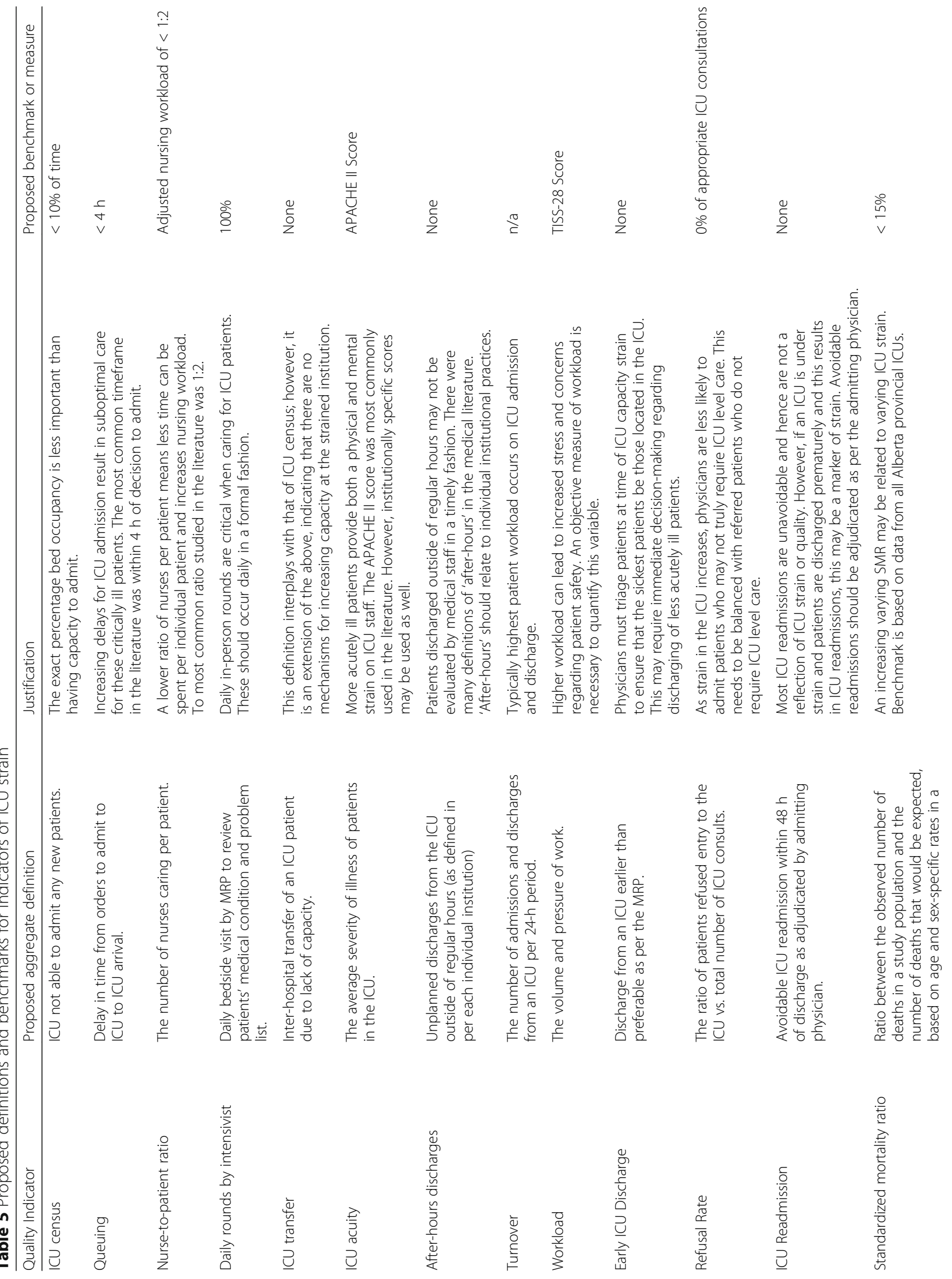




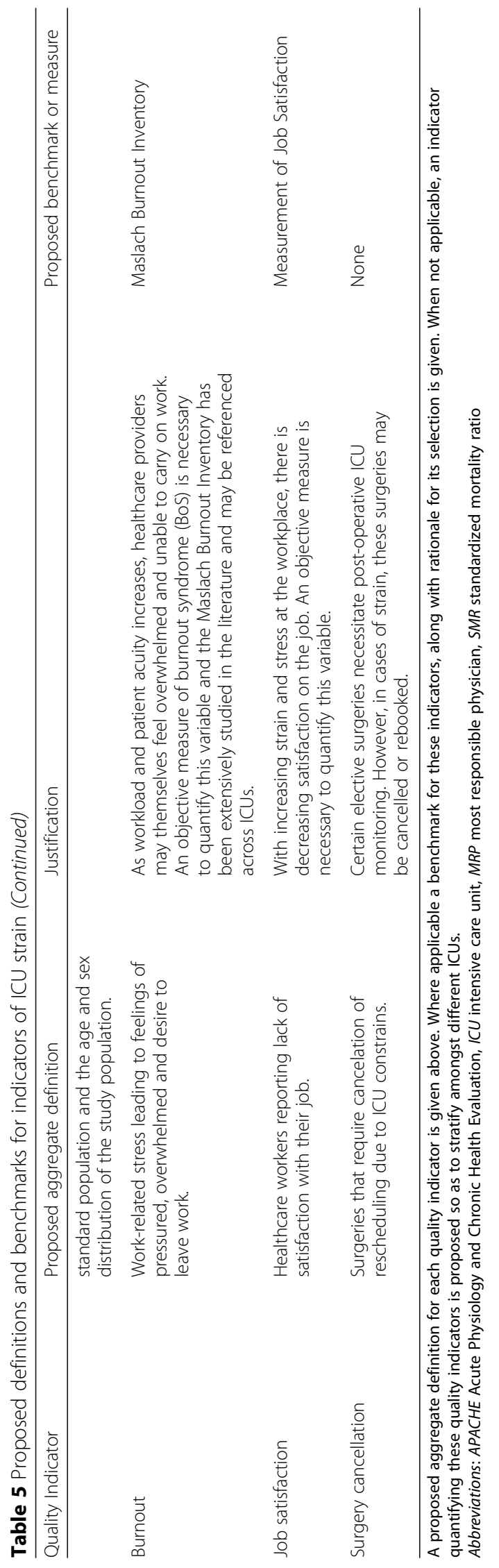




\section{Key messages}

- Strained ICU capacity is associated with alterations in care processes and adverse outcomes.

- This systematic review has identified and characterized 16 potential indicators of strained ICU capacity.

- Indicators were variable in their operational definitions and few were evaluated for scientific acceptability, usability or feasibility.

- The most common indicators of strain showed overlap with recommended ICU key performance indicators (i.e., ICU acuity, ICU readmission, afterhours discharge, and occupancy).

- Several indicators of strain could readily be implemented and would likely add value, particularly if clustered as a dashboard or index, to provide holistic ICU-specific information on key contributors to strain.

\section{Additional files}

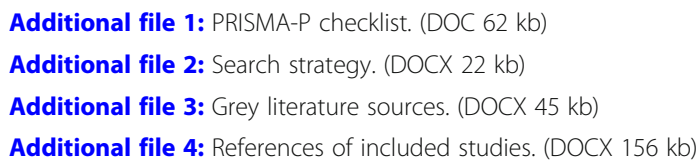

\section{Abbreviations}

ARCHE: Alberta Research Centre for Health Evidence; CENTRAL: Cochrane Central Register of Controlled Trials; HER: Electronic health record; ICU: intensive care unit; KPI: Key performance indicator; NOS: NewcastleOttawa Quality Assessment Scale; SMR: Standardized mortality ratio

\section{Acknowledgements}

The authors gratefully acknowledge the contribution of Tara Landry, MLIS for her peer review of the Ovid MEDLINE search strategy. SMB is support by a Canada Research Chair (CRC) in Critical Care Nephrology. HTS is supported by an Embedded Clinician Researcher Award from the Canadian Institutes of Health Research.

\section{Funding}

This work was funded by in part by a Partnership for Research and Innovation in the Health System (PRIHS) grant, Alberta Innovates (Grant Record Number: 201300467).

\section{Availability of data and materials}

The authors declare that all data supporting the findings of this study are available within the article and its Additional files.

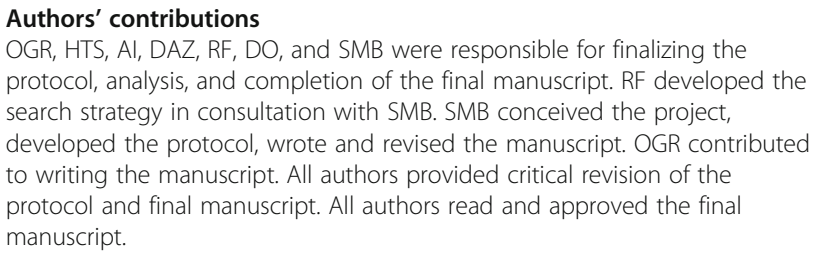
protocol, analysis, and completion of the final manuscript. RF developed the search strategy in consultation with SMB. SMB conceived the project, developed the protocol, wrote and revised the manuscript. OGR contributed to writing the manuscript. All authors provided critical revision of the protocol and final manuscript. All authors read and approved the final manuscript.

Ethics approval and consent to participate Not applicable.
Consent for publication

Not applicable.

\section{Competing interests}

The authors declare that they have no competing interests.

\section{Publisher's Note}

Springer Nature remains neutral with regard to jurisdictional claims in published maps and institutional affiliations.

\section{Author details \\ ${ }^{1}$ Department of Critical Care Medicine, Faculty of Medicine and Dentistry, University of Alberta, 2-124 Clinical Sciences Building, 8440 - 112th Street, Edmonton, AB T6G 2B7, Canada. ${ }^{2}$ School of Public Health, University of Alberta, Edmonton, $A B$, Canada. ${ }^{3}$ Critical Care Strategic Clinical Network, Alberta Health Services, Edmonton, AB, Canada. ${ }^{4}$ Department of Critical Care Medicine, Cumming School of Medicine, University of Calgary, Calgary, AB, Canada. ${ }^{5}$ Department of Community Health Sciences, Cumming School of Medicine, University of Calgary, Calgary, AB, Canada. ${ }^{6}$ O'Brien Institute for Public Health, Cumming School of Medicine, University of Calgary, Calgary, $A B$, Canada. ${ }^{7}$ Alberta School of Business, University of Alberta, Edmonton, AB, Canada. ${ }^{8}$ Alberta Research Center for Health Evidence (ARCHE), Department of Pediatrics, University of Alberta, Edmonton, AB, Canada.}

Received: 27 November 2017 Accepted: 5 February 2018

Published online: 27 March 2018

\section{References}

1. Bagshaw SM, Opgenorth D, Potestio M, Hastings SE, Hepp SL, Gilfoyle E, McKinlay D, Boucher P, Meier M, Parsons-Leigh J, Gibney RT, Zygun DA, Stelfox HT. Healthcare provider perceptions of causes and consequences of ICU capacity strain in a large publicly funded integrated health region: a qualitative study. Crit Care Med. 2017;45:e347-56.

2. Halpern SD. ICU capacity strain and the quality and allocation of critical care. Curr Opin Crit Care. 2011;17:648-57.

3. Bagshaw SM, Wang X, Zygun DA, Zuege D, Dodek P, Garland A, Scales DC, Berthiaume L, Faris P, Chen G, Opgenorth D, Stelfox HT. Association between strained capacity and mortality among patients admitted to intensive care: a path-analysis modeling strategy. J Crit Care. 2017:43:81-7.

4. Daud-Gallotti RM, Costa SF, Guimaraes T, Padilha KG, Inoue EN, Vasconcelos TN, da Silva Cunha Rodrigues F, Barbosa EV, Figueiredo WB, Levin AS. Nursing workload as a risk factor for healthcare associated infections in ICU: a prospective study. PLoS One. 2012:7:e52342.

5. Weissman GE, Gabler NB, Brown SE, Halpern SD. Intensive care unit capacity strain and adherence to prophylaxis guidelines. J Crit Care. 2015:30:1303-9.

6. Hua M, Halpern SD, Gabler NB. Wunsch H, (2016) Effect of ICU strain on timing of limitations in life-sustaining therapy and on death. Intensive Care Med. 2016:42(6):987-94.

7. Stelfox HT, Hemmelgarn BR, Bagshaw SM, Gao S, Doig CJ, NijssenJordan C, Manns B. Intensive care unit bed availability and outcomes for hospitalized patients with sudden clinical deterioration. Arch Intern Med. 2012:172:467-74.

8. Dodek PM, Wong H, Norena M, Ayas N, Reynolds SC, Keenan SP, Hamric A, Rodney P, Stewart M, Alden L. Moral distress in intensive care unit professionals is associated with profession, age, and years of experience. $J$ Crit Care. 2016:31:178-82.

9. Gabler NB, Ratcliffe SJ, Wagner J, Asch DA, Rubenfeld GD, Angus DC, Halpern SD. Mortality among patients admitted to strained intensive care units. Am J Respir Crit Care Med. 2013;188:800-6.

10. Wagner J, Gabler NB, Ratcliffe SJ, Brown SE, Strom BL, Halpern SD. Outcomes among patients discharged from busy intensive care units. Ann Intern Med. 2013;159:447-55.

11. Shamseer L, Moher D, Clarke M, Ghersi D, Liberati A, Petticrew M, Shekelle P, Stewart LA, Group P-P. Preferred reporting items for systematic review and meta-analysis protocols (PRISMA-P) 2015: elaboration and explanation. BMJ. 2015;349:97647.

12. Soltani SA, Ingolfsson A, Zygun DA, Stelfox HT, Hartling L, Featherstone R, Opgenorth D, Bagshaw SM. Quality and performance measures of strain on intensive care capacity: a protocol for a systematic review. Syst Rev. 2015:4:158. 
13. Sampson M, McGowan J, Cogo E, Grimshaw J, Moher D, Lefebvre C. An evidence-based practice guideline for the peer review of electronic search strategies. J Clin Epidemiol. 2009;62:944-52.

14. Rewa OG, Villeneuve PM, Lachance P, Eurich DT, Stelfox HT, Gibney RTN, Hartling L, Featherstone R, Bagshaw SM. Quality indicators of continuous renal replacement therapy (CRRT) care in critically ill patients: a systematic review. Intensive Care Med. 2017:43:750-63.

15. Higgins JP, Altman DG, Gotzsche PC, Juni P, Moher D, Oxman AD, Savovic J, Schulz KF, Weeks L, Sterne JA, Cochrane Bias Methods G, Cochrane Statistical Methods G. The Cochrane Collaboration's tool for assessing risk of bias in randomised trials. BMJ. 2011;343:d5928.

16. Donabedian A. Evaluating the quality of medical care. Milbank Mem Fund Q. 1966:44(Suppl):166-206.

17. McGlynn EA. Introduction and overview of the conceptual framework for a national quality measurement and reporting system. Med Care. 2003:41:11-7.

18. Institute of Medicine. Crossing the quality chasm: a new health system for the 21st century. Washington, DC: National Academy Press; 2001.

19. Chrusch CA, Martin CM, Project TQ. Quality improvement in critical care: selection and development of quality indicators. Can Respir J. 2016;2016: 2516765.

20. Rhodes A, Moreno RP, Azoulay E, Capuzzo M, Chiche JD, Eddleston J, Endacott R, Ferdinande P, Flaatten H, Guidet B, Kuhlen R, Leon-Gil C, Martin Delgado MC, Metnitz PG, Soares M, Sprung CL, Timsit JF, Valentin A, Task Force on Safety and Quality of European Society of Intensive Care Medicine. Prospectively defined indicators to improve the safety and quality of care for critically ill patients: a report from the Task Force on Safety and Quality of the European Society of Intensive Care Medicine (ESICM). Intensive Care Med. 2012;38:598-605.

21. Garland A, Olafson K, Ramsey CD, Yogendran M, Fransoo R. Epidemiology of critically ill patients in intensive care units: a population-based observational study. Crit Care. 2013;17:R212

22. Halpern NA, Pastores SM, Greenstein RJ. Critical care medicine in the United States 1985-2000: an analysis of bed numbers, use, and costs. Crit Care Med. 2004;32:1254-9.

23. Gershengorn HB, Iwashyna TJ, Cooke CR, Scales DC, Kahn JM, Wunsch H. Variation in use of intensive care for adults with diabetic ketoacidosis*. Crit Care Med. 2012:40:2009-15.

24. Rhodes A, Ferdinande P, Flaatten H, Guidet B, Metnitz PG, Moreno RP. The variability of critical care bed numbers in Europe. Intensive Care Med. 2012; 38:1647-53.

25. Azevedo LC, de Souza IA, Zygun DA, Stelfox HT, Bagshaw SM. Association between nighttime discharge from the intensive care unit and hospital mortality: a multi-center retrospective cohort study. BMC Health Serv Res. 2015;15:378

26. Cardoso LT, Grion CM, Matsuo T, Anami EH, Kauss IA, Seko L, Bonametti AM. Impact of delayed admission to intensive care units on mortality of critically ill patients: a cohort study. Crit Care. 2011;15:R28.

27. Chalfin DB, Trzeciak S, Likourezos A, Baumann BM, Dellinger RP, group D-Es. Impact of delayed transfer of critically ill patients from the emergency department to the intensive care unit. Crit Care Med. 2007;35:1477-83.

28. Santamaria JD, Duke GJ, Pilcher DV, Cooper DJ, Moran J, Bellomo R, Discharge RES. The timing of discharge from the intensive care unit and subsequent mortality. A prospective, multicenter study. Am J Respir Crit Care Med. 2015;191:1033-9.

29. Wallace DJ, Seymour CW, Kahn JM. Hospital-level changes in adult ICU bed supply in the United States. Crit Care Med. 2017;45:e67-76.

30. Town JA, Churpek MM, Yuen TC, Huber MT, Kress JP, Edelson DP. Relationship between ICU bed availability, ICU readmission, and cardiac arrest in the general wards. Crit Care Med. 2014;42:2037-41.

31. Benoit MA, Bagshaw SM, Norris CM, Zibdawi M, Chin WD, Ross DB, van Diepen S. Postoperative complications and outcomes associated with a transition to 24/7 intensivist management of cardiac surgery patients. Crit Care Med. 2017:45:993-1000

32. Brown SE, Ratcliffe SJ, Halpern SD. An empirical derivation of the optimal time interval for defining ICU readmissions. Med Care. 2013;51:706-14.

33. Al-Jaghbeer MJ, Tekwani SS, Gunn SR, Kahn JM. Incidence and etiology of potentially preventable ICU readmissions. Crit Care Med. 2016;44:1704-9.

34. Kerlin MP, Harhay MO, Vranas KC, Cooney E, Ratcliffe SJ, Halpern SD. Objective factors associated with physicians' and nurses' perceptions of intensive care unit capacity strain. Ann Am Thorac Soc. 2014;11:167-72.

\section{Submit your next manuscript to BioMed Central and we will help you at every step:}

- We accept pre-submission inquiries

- Our selector tool helps you to find the most relevant journal

- We provide round the clock customer support

- Convenient online submission

- Thorough peer review

- Inclusion in PubMed and all major indexing services

- Maximum visibility for your research

Submit your manuscript at www.biomedcentral.com/submit 